\title{
Herencias destruidas, la afección por el entorno: El desbarrancadero de Fernando Vallejo
}

\author{
Destroyed Heritages, affection for the environment: \\ El desbarrancadero by Fernando Vallejo \\ Heranças destruídas, a afeção pelo entorno: El desbarrancadero \\ (O Despenhadeiro) de Fernando Vallejo
}

\section{Andrés Pérez Sepúlveda}

UNIVERSIDAD SIMÓN BOLÍVAR, CARACAS, VENEZUELA

Profesor del Departamento de Lengua y Literatura de la Universidad

Simón Bolívar, Caracas y Magíster en Literatura Latinoamericana de la misma institución. Es autor del "Prólogo" a Los pueblos

hispanoamericanos en el siglo XX de Ricardo Beltrán y Rózpide

(Biblioteca Ayacucho, 2011), "La relación entre la historia y la literatura:

(con)fusión para (re)presentar la experiencia (des)humana" (Argos,

Vol. $29 \mathrm{~N}^{\circ} 56$, 2012). Correo electrónico: andresepulveda@usb.ve

Artículo de reflexión

Documento accesible en línea desde la siguiente dirección: http://revistas.javeriana.edu.co

doi: 10.11144/Javeriana.cl19-38.hdae 


\section{Resumen}

Este artículo tiene el propósito de estudiar la novela $E l$

desbarrancadero de Fernando

Vallejo como un modo alterno de explorar la identidad contraviniendo los discursos históricos oficiales. A través de los conceptos de memoria, herencia y afecto, será posible rastrear los modos en que se elabora una reflexión sobre la pertenencia familiar y nacional. El resultado será una narración contestataria, recelosa, punzante y cuestionadora, que coloca bajo sospecha la visión unitaria de la nación, mostrando la fisura que en la sociedad colombiana ha generado la violencia.

Palabras clave: memoria; herencia; familia; nación; afecto; pertenencia

\section{Abstract}

This essay intends to approach Fernando Vallejo's novel $E l$ desbarrancadero as a distinctive model for the study of individual and collective identity. Memory, legacy and affection are seen as conceptual tools for the understanding of people's sense of national belonging. We focus in the need to search for a new, sharp and biting narrative necessary for questioning the official approach of a nation as an unitary entity, and for the understanding of the rift that political violence has generated in Colombian society.

Keywords: memory; legacy; family; nation; affection; belonging

\section{Resumo}

Este artigo tem o propósito de estudar o romance $E l$ desbarrancadero de Fernando Vallejo como modo alterno de explorar a identidade contravindo os discursos históricos oficiais. Através dos conceitos de memória, herança e afeto, será possível rastejar os modos em que a reflexão sobre pertencimento familiar e nacional é elabora. $\mathrm{O}$ resultado vai ser uma narração contestatária, receosa, aguçada e questionadora que coloca sob suspeita a visão unitária da nação, mostrando a fissura que a violência tem gerado na sociedade colombiana

Palavras-chave: memória; herança; família; nação; afeto; pertencia

\section{Cómo citar este artículo:}

Sepúlveda, Andrés. "Herencias destruidas, la afección por el entorno: $E l$ desbarrancadero de Fernando Vallejo". Cuadernos de Literatura 19.38 (2015): 462-483. http://dx.doi.org/10.11144/Javeriana.cl19-38.hdae 
EXISTE UNA RELACIÓN cada vez más estrecha entre el interés por el pasado y la producción literaria en América Latina. Los sucesos narrados desde la ficción buscan elaborar una respuesta alternativa a los discursos hegemónicos sobre los acontecimientos pretéritos. Ciertamente, la literatura en este caso no pretende sustituir a la historiografía o a las disciplinas sociales en su búsqueda por comprender los vericuetos del devenir humano. Las narrativas que abordan el tema de la memoria, el recuerdo, la subjetividad y su relación con el entramado nacional apuntan a un cuestionamiento permanente de los postulados que estructuran y rigen a las sociedades, anteponen la sospecha por encima del acierto, diseccionan y testifican sobre las marcas y registros que el poder inscribe sobre los cuerpos.

Pareciera que el optimismo característico de la modernidad acerca de un mejor futuro para la humanidad pierde fuerza ante la creciente ola de consumo de discursos sobre el pasado. Y no es tanto la historia como totalidad sin fisuras la que interesa sino aquella que indaga sobre el dato menor, la vida íntima, las reconstrucciones de la cotidianidad, el testimonio y el recuerdo personal. Un conjunto de discursos asentados en una actitud de desconfianza generalizada en torno a los discursos totalizadores. Es decir, parte del resultado de la modernidad ha sido, precisamente, interpelar la veracidad de los postulados que la sostienen. En este sentido, el pasado como aspecto cognoscible, seguro, documentado y verosímil ha entrado en crisis, así como otras áreas del saber.

Es por ello que pretendo circunscribir el presente artículo dentro del ámbito de las ficciones de la memoria como una fuente alternativa para reflexionar sobre los modos en que la literatura vuelve al pasado y se pregunta sobre otras formas de imaginar la nación desde la rememoración de la casa y de la familia y, también, sobre la importancia de enfrentarse con los legados para cuestionarlos, incluso desautorizarlos.

Ahora bien, siguiendo la reflexión sobre la modernidad, podría decir que el papel que juega la nación como factor aglutinador y de concertación social es clave. Un pueblo reunido en torno a tradiciones y un legado común, un destino compartido con sus errores y aciertos forman parte del repertorio narrativo de lo nacional. Esa narrativa apela a la emoción, al sentimiento unitario, y demanda lealtad a cada uno de los individuos de la nación. El componente afectivo articula y capitaliza la nación, surge un espacio que se posiciona como zona franca, incluyendo sus márgenes. Acá cabría mencionar lo que Homi Bhabha denomina "carácter liminar de la nación", un umbral donde opera lo colectivo y lo individual al mismo tiempo, visiones monumentales del pasado y también performativas, un tiempo disyuntivo de la nación. Me permito citar in extenso a Bhabha al respecto: 
El pueblo no consiste sólo en acontecimientos históricos o en partes de un cuerpo político patriótico. También es una estrategia retórica compleja de referencia social en la cual la reivindicación de representatividad provoca una crisis dentro del proceso de significación y exposición discursiva. Así pues, tenemos un territorio cultural cuestionado en el que el pueblo debe ser pensado en un tiempo doble; el pueblo son los "objetos" históricos de una pedagogía nacionalista, que le confiere al discurso una autoridad basada en el origen o el acontecimiento histórico ya dado o constituido; el pueblo son también los "sujetos" de un proceso de significación que deben borrar cualquier presencia previa u originaria del pueblo-nación para demostrar el principio prodigioso, viviente, del pueblo en tanto proceso continuo mediante el cual la vida nacional se redime y se significa como un proceso que se repite y se reproduce. Los retazos, remiendos y harapos de la vida cotidiana deben convertirse una y otra vez en los signos de una cultura nacional, mientras el acto mismo de la performance narrativa interpela un círculo cada vez mayor de sujetos nacionales. En la producción de la nación como narración existe una escisión entre la temporalidad continuista y acumulativa de lo pedagógico, y la estrategia repetitiva y recurrente de lo performativo. Es a través de este proceso de escisión que la ambivalencia conceptual de la sociedad moderna se convierte en el lugar de la escritura de la nación. (392)

Me interesa destacar el carácter ambivalente de la nación, sus escisiones y continuidades plasmadas en las diversas narrativas que un pueblo es capaz de generar sobre sí mismo. Me interesa, también, apropiarme de la reivindicación del sujeto como autor de dichas narrativas surgidas en un tiempo presente. Es decir, me propongo estudiar cómo las comunidades y las retóricas que las sustentan poseen un intervalo donde se diseminan y reconfiguran los sentidos en un devenir permanente, producto de la intervención y voluntad de los sujetos. Estos sujetos son protagonistas de hechos históricos que el poder intenta relatar a través de una versión unitaria de lo nacional, pero también han sufrido en carne propia los embates y consecuencias de la violencia dominante. De tal manera que es a través de la diferencia, del desacuerdo, que algunas narrativas intentan responder a las agresiones del poder y producen contrarrelatos que cuestionan e impiden la estabilidad y coherencia de la nación. Son historias que operan desde ese espacio liminar de la nación.

Estos sujetos muestran otro sentido de la comunidad, interpelan al poder y ponen en escena las laceraciones de los discursos totalizantes que buscan minimizar los errores borrando cualquier disonancia con el fin de asegurar la imagen de una nación estable. 
En estos contrarrelatos la memoria se despliega desde el ámbito privado e individual; de esta manera, el afecto adquiere una dimensión política contundente porque tiene visibilidad, se hace público. Es el giro de la subjetividad, la avanzada de lo que no se encuentra domesticado por la "policía discursiva", lo no sometido a la ortopedia del discurso convencional. Entonces, la representación del afecto es el componente utilizado por algunas narrativas para explorar la posibilidad de pensar la nación desde otros supuestos. El afecto sería el capital por antonomasia para reconstruir la mermada nación contemporánea e intentar devolverle al sujeto alguna posibilidad de intervención política en ese espacio quebrado.

De las múltiples posibilidades y perspectivas que la literatura latinoamericana ofrece para indagar sobre los modos de poner en escena la memoria, elegí una que regresa al pasado desde el ámbito privado, familiar y afectivo para, desde allí, cuestionar la genealogía de pertenencia tanto familiar como nacional y mostrar otros modos de afiliarse o no a su dictado. Se trata de la novela $E l$ desbarrancadero (2001) de Fernando Vallejo. Ciertamente, este autor colombiano genera un cuestionamiento radical de dos instituciones centrales: la familia y la nación. En este sentido, estamos ante una literatura que se posiciona fuera de los discursos dominantes y propone otros modos de "hacer" y "usar" la memoria.

En esta novela resulta particularmente importante la figura del heredero del patrimonio familiar y nacional como aquel que se enfrenta con los legados del pasado para interpretarlos y releerlos a la luz del presente. Toda herencia implica una relación con aquello que ya no está. Destaca la importancia de un diálogo entre los vivos y los muertos, y muestra en qué medida la presencia del ausente exige, de parte del vivo, una confrontación con la deuda que su desaparición supone y una responsabilidad por el legado recibido para resguardarlo y continuarlo (Benjamin La dialéctica en suspenso 47). Responsabilidad que está en manos de los miembros del cuerpo familiar, quienes son los albaceas de ese pasado, de esa memoria. Es decir, hacerse cargo del pasado significa, de parte del legatario, un esfuerzo de lectura y de interpretación de la herencia para asegurar al colectivo de pertenencia -familia, clase, nación, otros- una continuidad del patrimonio identitario, simbólico, económico.

Ahora bien, la memoria es una figuración del pasado, un relato que nos permite reescribirlo y reimaginarlo. Esa figuración posiciona al sujeto de un modo determinado frente a su origen, genealogía, proveniencia, familia, padres, que configuran un marco que opera sobre la identidad y los vínculos que la sostienen. Sin embargo, ¿qué sucede cuándo un hijo reconoce la herencia que recibe como un patrimonio que es necesario intervenir y rechazar?; ¿Qué supone heredar para desheredar y así interpelar el vínculo recibido para, desde ese mismo gesto, 
asumir una posición en relación a su mandato? Ciertamente, esta pregunta constituye el eje central del análisis que propongo de la novela El desbarrancadero de Fernando Vallejo. Aunque en la literatura colombiana existen otras novelas donde se desarrollan reflexiones en torno a la herencia y la memoria, tanto familiar como nacional, he optado por profundizar en el análisis de esta sola.

En este relato la apacible imagen de una familia convencional de Medellín es cuestionada por uno de sus propios miembros, Fernando, el protagonista, quien revisa la historia de la familia desde el escepticismo y el rechazo. Su lugar de enunciación parte del gesto furibundo de responder a la pregunta por el mandato de la herencia de una manera distinta, díscola y contestataria. Su gesto es el de contar el pasado familiar haciendo énfasis en sus zonas enfermas y desequilibradas, en sus quiebres y fracturas que apuntan a situaciones de enfermedad y locura. Fernando no recurre a la memoria para honrar el patrimonio familiar ni mucho menos continuarlo; recurre a ella para señalar sus faltas -que, precisamente, están dadas por aquello que es rechazado del cuerpo familiar (la locura, la maldad, la enfermedad)-, que arrojan un resultado deficitario del patrimonio legado y muestran en qué medida la sangre no es una garantía en la que se puede confiar ni tampoco una riqueza. Para Fernando este patrimonio desmembrado posee datos suficientes para reconstruir la historia y repensar la herencia familiar a partir de sus quiebres, lo que lo lleva a posicionarse en su contra y a proponer, a través de la escritura, otra manera de leerla y procesarla.

$\mathrm{Su}$ propuesta es desestabilizadora:

Los recuerdos son una carga necia, doctor, un fardo estúpido. Y el pasado un cadáver que hay que enterrar prontico o se pudre uno en vida con él. Se lo digo yo que inventé el borrador de recuerdos que tan útil me ha sido, y del que le estoy haciendo en estos precisos momentos una demostración. Mire, vea, fíjese: barre con toda la basura del coconut. (El desbarrancadero 98)

El narrador acá descrito se rebela ante la herencia que le corresponde como hijo. Se niega a la imposición de un patrimonio, por eso considera necesario intervenirlo a través de la selección del recuerdo, barriendo el pasado como si fuera un desperdicio que necesita eliminar porque constituye un pesado fardo que el narrador arrastra como un cadáver del que se quiere liberar. La manera de intervenirlo es editando la memoria individual, aquella que es atravesada fundamentalmente por el afecto, la querencia obtenida de aquellos miembros de la familia que él más añora.

La memoria de Fernando intenta operar desde los cortes que él selecciona, lo que implica la construcción de una trama discontinua e incompleta. Es decir, 
el acto de borrar los recuerdos sirve para cortar lo que estorba, barrer con lo que impide ejercer el derecho a administrar la herencia como mejor convenga, incluso si eso implica traicionarla.

Se trata de mirar hacia el pasado no sólo para ejercer la acción de rememorar y confirmar una identidad "desbarrancada" sino, sobre todo, para interpelar la lógica recibida e impuesta del mandato y hacer que produzca nuevas significaciones; una suerte de lectura a contrapelo de los eventos familiares a fin de observarlos desde la deriva y el tajo (Foucault Microfísica del poder 20). La herencia es un mandato intransferible e impostergable y Fernando responde a esta tarea desde la duda del legatario, sin dar reparos a la imposición de un índice de bienes acumulados e incrustados en el cuerpo familiar. Ante el patrimonio decide constituirse en un administrador del caos recibido, aunque el inventario de los recuerdos arroje un saldo de quiebra potencial.

El heredero-narrador cuenta el pasado de forma aleatoria, conforme se van suscitando en él los motivos y estímulos que lo inducen a recordar. El relato está invadido de anécdotas que dan paso a una narración compulsiva y agolpada de los recuerdos, a través de saltos temporales hechos de retazos de la memoria. Esos retazos elaboran un entramado que socava la autoridad familiar poniéndola bajo sospecha. Fernando asume la voz del juez que sentencia y da la última palabra sobre los valores que sustentan el orden recibido por las autoridades parentales. Actúa como quien está al acecho del error para dejarlo al descubierto, le interesa azuzar lo adquirido para develar los mecanismos de coacción, esos engranajes establecidos por la costumbre y la obediencia ciega. Asume el rol de hermeneuta del pasado familiar, no de su exegeta y se constituye, de este modo, en un "descifrador de enigmas" (Nietzsche La genealogía de la moral 197).

Llama la atención que en esta novela los enigmas están en la médula de la familia; es decir, que es la misma familia la que se vuelve en zona siniestra y ajena donde es imposible reconocerse. Lo que es normal y convencional dentro de un hogar familiar para el narrador se vuelve sospechoso, extraño, ajeno y motivo de desconfianza.

Los valores que consagran el orden familiar (integración, solidaridad, afecto, confianza y tradición) no sólo están presentes en el hogar del narrador sino que también forman parte de la nación. De manera que existe una vinculación entre la casa familiar y la casa nacional que las vuelve complementarias y además hace posible leer una en la otra. Es decir, los precarios estatutos familiares adquieren visibilidad junto a los del Estado. Ahí donde el orden es presentado como algo sólido y estable, infalible e inquebrantable, aparece el heredero-narrador señalando su dimensión corrupta, enferma y sospechosa. De esta manera, aquello que del 
cuerpo familiar se tiende a velar, a enmascarar o silenciar (suicidio, enfermedad y locura), adquiere un rol protagónico porque sirve para comprender y explicar el desorden subyacente al orden hegemónico:

De preñez en preñez, de parto en parto, poseída por una furia reproductiva que la impelía a amontonar hijos y más hijos en una casa de espacio finito (...) tratando de ajustar los doce apóstoles pero sin lograrlo porque también le nacían mujeres, entre niños y niñas la Loca pasó por el número doce y se siguió rumbo al veinte. A los doce mi casa era un manicomio; a los veinte el manicomio era un infierno. Una Colombia en chiquito. Acabamos por detestarnos todos, por odiarnos fraternalmente los unos a los otros hasta que la vida nos dispersó. (El desbarrancadero, 159)

En la capacidad reproductiva radica la esencia del deterioro paulatino de la sociedad colombiana, y para Fernando esto forma parte de una problemática irreversible que fomenta la continuación de un linaje monstruoso. El espacio reducido por la aglomeración de personas viviendo en hacinamiento permanente instaura formas de vida en el hogar que no se relacionan con el supuesto bienestar que vivir en familia implica. Si el hogar deviene en manicomio, entonces la cordura deja de ser el eje que gobierna la casa. Lo mismo podría decirse de la nación, el mismo narrador plantea que su hogar es una "Colombia en chiquito": A ver, a ver, a ver, ¿qué es lo que vemos? Estragos y más estragos y entre los estragos las cabras, la monstruoteca que se apoderó de mi ciudad. Nada dejaron, todo lo tumbaron, las calles, las plazas, las casas y en su lugar construyeron un Metro, un tren elevado que iba y venía de un extremo al otro del valle, en un ir y venir tan vacío, tan sin objeto, como el destino de los que lo hicieron. ;Colombian people, I love you! Si no os reprodujerais como animales, oh pueblo, viviríais todos en el centro. ¡Raza tarada que tienes alma de periferia! (53)

Es decir, la casa funciona como clave alegórica del espacio nacional y viceversa. El espacio distribuido y controlado de la casa es amenazado por tensiones, divisiones y odios irremediables. La locura se instaura como principio organizador hasta que muchos deciden tomar la iniciativa de abandonarla. El mismo Fernando es un sujeto que vive en un (auto)exilio provocado por las diferencias y exclusiones del espacio familiar/nacional.

No puedo dejar de percibir la relación que existe entre lo íntimo/privado y lo colectivo/público a lo largo de la trama de la novela, como un modo de intervenir políticamente los espacios que se consideran estables y seguros y que están gobernados por lo siniestro. 
El afán reproductivo del pueblo colombiano equivale al de la familia del narrador; la ciudad de Medellín y el territorio nacional no soportan un crecimiento poblacional que perjudica a los mismos habitantes y esto instaura una nueva forma de vida condicionada por la estrechez del espacio físico.

Una casa llena de hermanos que terminan por desconfiar los unos de los otros, equivale a un país lleno de gente que a su vez reproduce más gente e instaura la sospecha y desconfianza como agentes espontáneos de socialización. El relato familiar se ve continuamente desplazado hacia el terreno nacional, la geografía del hogar y la de la ciudad ubican al narrador dentro de unas coordenadas espaciales donde se inserta su biografía. Es decir, la casa y Medellín funcionan como una unidad indisociable desde la cual Fernando actúa y despliega su versión personal de los hechos familiares y nacionales. La casa no es una muralla que protege a sus hijos de los ataques y confrontaciones del exterior; la violencia que opera en la nación adquiere una fuerza e ímpetu suficiente para penetrar la intimidad familiar y hacer que sucumba a su propia lógica.

Si la casa ya no asegura cobijo ni amparo entonces el espacio se vuelve siniestro, una vitrina que expone el cuerpo familiar y lo deja desprotegido ante sus propios monstruos y los de la nación. Ante la situación de deterioro, el heredero-narrador hace uso de la sospecha y cuestiona el mandato de preservar lo legado como patrimonio certero; por eso insiste en mostrar sus fisuras e intervenir sus zonas más hostiles y rotas. Fernando orienta sus acciones hacia la conformación de un texto que reescribe la familia y el país para desmontar su monumentalidad.

El límite entre lo privado y lo público no está definido en el relato. La descripción de la casa (esfera íntima) tiende a inscribirse sobre la superficie de la nación (esfera pública), es decir, hace que el narrador invoque las semejanzas entre ambos espacios. Los bienes recibidos en estos espacios revelan un patrimonio tangible e intangible, defenestrado por un heredero desconcertado. En vez de tomarlo y conservarlo como obra acabada e incuestionable, se posiciona como un funcionario que avalúa el deterioro que hay en la propiedad a causa del pasar del tiempo, que da cuenta de las fisuras y grietas que debilitan la estructura y la hacen más friable, próxima al derrumbe. La intimidad pertenece al reino de lo difuso y se mimetiza con lo social, de allí la simultaneidad y semejanzas entre una casa y un país arruinados, rumbo al desbarrancadero.

Pareciera que el pasado familiar fuera una metonimia del nacional; hay una correspondencia y complementariedad entre uno y otro. Leer la nación es leer en sus fracturas la sangre, el apellido, la familia. Es como si toda la estructura que soporta la familia y la nación se hubiese derrumbado. En este sentido, Fernando 
desea desvincularse de todo lo recibido a fin de trazar otro posible devenir del apellido y la estirpe:

Yo no soy hijo de nadie. No reconozco la paternidad ni la maternidad de ninguno ni de ninguna. Yo soy hijo de mí mismo, de mí espíritu, pero como el espíritu es una elucubración de filósofos confundidores, entonces haga de cuenta usted un ventarrón, un ventarrón del campo que va por el terregal sin ton ni son ni rumbo levantando tierra y polvo y ahuyentando pollos. ( $E l$ desbarrancadero 44)

El heredero rechaza a sus progenitores y le dice no a la sangre y a la estirpe. Es decir, la partenogénesis propuesta en el relato es una simulación compensatoria que apunta directamente a la eliminación del parentesco por consanguinidad. El acto de rechazar la sangre es una apuesta nominal orientada a una orfandad voluntaria. Hay que recordar que el heredero descrito acá es uno al que le duele el legado y por eso intenta corregirlo a partir de su negación. Esa consanguinidad rechazada simbólicamente es comprendida en el modo en que se narra la imagen materna. En efecto, la madre es "La Loca", y el narrador no refrenda su parentesco con ella porque su imagen está asociada a lo que más detesta de la familia y del país.

Atacar a la figura materna implica una estrategia que confronta el potencial de reproducción que esta posee y que amenaza a los que habitan en la casa porque la vuelve lugar de asfixia y de confrontaciones. Atacar a la madre implica intervenir su autoridad, bien sea por el potencial reproductivo que esta posee como por la veneración que demanda. El gesto de rebelión del heredero-narrador no sólo implica la desautorización de la madre sino de varias instancias de poder, aquellas que tienden a socavar la voluntad individual en aras de la conservación del bienestar colectivo, siempre bajo sospecha en todo el relato.

El heredero-narrador rechaza la seguridad que otorga un apellido, y apuesta por una orfandad que le permite salvar las únicas zonas no corruptas o enfermas de su pasado; no es un legatario pasivo ni conforme. Quiere elegir, rechazar, problematizar aquello que le es transmitido, e incluso proponer, a través de la escritura, otra herencia que consiste justamente en aquello que la herencia recibida no otorga. El relato escéptico del protagonista no constituye una respuesta al llamado de la especie sino su intervención y rechazo. Es una muestra de que la herencia también se puede construir y la manera de hacerlo, en su caso, es escribiendo no para repetirla o conservarla sino para rehacerla a partir de sus carencias.

El desmantelamiento del pasado, en lo que este puede tener de monumentalidad, desplaza la narración hacia la vida íntima del autor al tiempo que establece una relación estrecha con el entorno nacional. Esa vinculación conlleva 
una confrontación con las instancias hegemónicas, consideradas por el legatario como las causantes de todo el deterioro paulatino de la casa/nación. En efecto, la Familia, la Iglesia Católica y el Estado forman una tríada capaz de sujetar a los ciudadanos de una nación, de controlarlos y someterlos. Instancias de poder que parten de una concepción patronímica de la memoria.

En el caso de la familia ya se ha visto la confrontación asumida por Fernando, una animadversión que llega hasta el extremo de intentar romper los vínculos de consanguinidad con la figura materna. Sin embargo, habría que incorporar las figuras de la Iglesia y el Estado a fin de mostrar el panorama completo de los mecanismos de coaptación de la sociedad colombiana enmascarado en instituciones y soportado por una serie de prácticas sociales de vieja raigambre.

El gesto de rechazo del heredero-narrador de su pasado permite entrever no solo su capacidad de desvincularse simbólicamente del orden familiar e institucional impuesto, sino también su necesidad de releer la memoria familiar y seleccionar las zonas más torcidas, aquellas que requieren una relectura para justificar la conveniencia de su intervención. Es entonces desde la duda y el cuestionamiento de donde el protagonista de la historia desea configurar el relato familiar y nacional.

No hay argumento capaz de evitar que el protagonista desafíe, cuestione y reproche la institucionalidad colombiana. No existen reparos en la manera en que el narrador atenta contra todo aquello que pertenezca al principio normativo y hegemónico que rige las instituciones colombianas. Ahora bien, su actitud busca diezmar el halo incuestionable que existe alrededor de estas instituciones donde la tradición nunca es puesta bajo cuestionamiento; busca señalar las debilidades del orden instituido para configurar otros modos de pensar la familia y la nación.

Las referencias a la Iglesia apuntan fundamentalmente a una crítica acerca del papel que ha jugado esta institución en la conformación de prácticas regulatorias del comportamiento que apuntan directamente a normalizar a los miembros de la comunidad:

-¡Al diablo con estos tartufos agoreros! Que no entre ni uno más a esta casa.

En ese momento me enteré de que un año atrás, mientras papi se moría, la Loca había llamado en un descuido mío a uno de estos buitres ensotanados para que le administrara la extremaunción.

${ }_{-}{ }_{\mathrm{d}} \mathrm{Y}$ para qué diablos necesitaba la extremaunción? Si con cincuenta años de matrimonio o infierno no pagó en vida esa pobre víctima lo que pudiera deber de purgatorio, entonces yo no sé con qué.

$\mathrm{Y}$ al terrible matacuras que hay en mí, descendiente rabioso de los liberales radicales colombianos del siglo XIX como Vargas Vila y Diógenes Arrieta, de 
la Revolución Francesa, el marqués de Sade, Renán, Voltaire, sectario, hereje, impío, ateo, apóstata, blasfemador, jacobino, le dio en aquella ocasión un ataque de ira santa que casi lo mata. Sobrevivió porque estaba escrito en el libro del destino que había de escribir éste. (176)

La intromisión de la Iglesia en los asuntos familiares desencadena en el narrador una reacción iracunda por considerarla una amenaza a la integridad del padre, una figura tutelar que agoniza y es incorporada al relato como parte de una representación que sirve de contrapeso a la de la madre.

Esta descripción no es solo el reflejo de una perspectiva anticristiana, eso es lo que pudiera leerse en un primer plano, sino más bien es una reacción coherente contra aquello que amenaza la percepción que tiene el heredero de su propio padre, una imagen de autoridad por la cual demuestra profundo afecto. De esta manera la figura del padre es neutralizada por dos figuras hegemónicas que contrarrestan la voluntad del protagonista a lo largo del relato: la madre y la Iglesia. La muerte es domesticada en una práctica continua que ratifica y deifica el orden, una "predispuesta continuidad" (Williams 138).

La ausencia del progenitor hace mella en el ánimo del heredero, le abre una herida que hace sistema con la de la pérdida de la abuela Raquel y la del hermano Darío. Por eso Fernando responde animosamente cuando la relación con sus seres queridos es interferida y distorsionada por la hegemonía de lo que en la familia y en la nación está desbarrancado, al mismo tiempo que amenaza lo que este desea preservar.

El recuerdo del padre aparece en la narración de forma aleatoria, para revelar otro modo de vivir en familia y contrarrestar el desgaste irremediable del entorno:

-¿Qué habrá después de la muerte, m’hijo? -me preguntó.

-Nada, papi -le contesté-. Uno no es más que unos recuerdos que se comen los gusanos. Cuando vos te murás seguirás viviendo en mí que te quiero, en mi recuerdo doloroso, y después cuando yo a mi vez me muera, desaparecerás para siempre.

${ }_{-} \mathrm{i} Y$ Dios?

-No existe. Y si no, mira en torno, por todas partes el dolor, el horror, el hombre y los animales matándose unos a otros. ¡Qué va a existir ese asqueroso! (82)

La muerte constituye una presencia significativa en el relato y produce una respuesta de parte del heredero-narrador ante el dolor que causa la ausencia de sus seres más queridos. Es en la pérdida donde se adquiere la conciencia del otro, 
aunque de este no quede más que nostalgia y duelo. Es por medio de la muerte que Fernando acude a la memoria y establece un pacto o alianza de solidaridad con el ausente.

El recuerdo del padre reivindica no sólo el amor que siente por él sino también sirve para oponerlo a las afectividades desgarradas de la casa. Lo que quiero decir es que a la "mala memoria" que teje el relato nacional y familiar, se le opone una "buena memoria" relacionada no solo con la figura paterna sino también con la de la abuela y el hermano. Por eso Fernando no repara en argumentos cuando habla del papel de la familia y la iglesia como instancias que incitan a la canonización de valores que afirman la dominación en sus prácticas tradicionales convirtiendo el afecto en algo calculado y rentable.

Ahora bien, una correlación similar entre las instancias de poder arriba mencionadas sería incompleta sin la mención de la responsabilidad que para Vallejo tiene el Estado en el deterioro paulatino de Colombia y de las relaciones familiares y afectivas.

Observa el narrador:

Mi tesis: que entre papas y presidentes y granujas de su calaña, elegidos en cónclave o no, a la humanidad la llevan como a una mula vendada con tapaojos rumbo al abismo.

- ¡Arre mula idiota, mula ciega! Un pasito más, que ya vas a caer.

De hecho ya está cayendo, y desde hace mucho, pero el problema es que no acaba de caer. Somos un moribundo terco que insiste en no morirse. (179)

La asociación y cooperación de la Iglesia y el Estado es en Colombia el resultado de una tradición vigente desde tiempos pasados que con sus prácticas garantiza y renueva la hegemonía de estas instituciones (125). En este sentido, el resultado será una marcha sin retorno y un sometimiento irrestricto a la norma que supone la regulación del conflicto. Esa regulación implica la imposición de una lectura única del pasado que no deja espacios para otras versiones. Al normalizarse este criterio unívoco de concepción de la historia que la convierte en monumento, el sujeto se encuentra sometido a un destino ineluctable que anula toda posibilidad de intervención y de acción política en la comunidad. Ante esto, el narrador se rebela denunciando la arbitrariedad de esta versión y contraponiéndole otra que cuestiona las "verdades" del pasado a la luz de las angustias y demandas del presente.

La falta de voluntad de los colombianos de reaccionar ante el "desbarrancadero" de la nación contribuye a menoscabar la capacidad del sujeto de intervenir en su entorno. En este sentido, el narrador reacciona y toma partido 
por una intervención de esa resignación generalizada a través del recurso de la memoria familiar y nacional como una manera de mostrar las monstruosidades de su identidad y pertenencia. El narrador no aspira a la verdad ni tampoco a una exposición lineal, coherente y estructurada de los hechos que le otorgue sentido al pasado. Por el contrario, la novela apela a la descripción de la enfermedad, la locura y la muerte del país y de la casa, es decir, a todo aquello que supone una amenaza de la imagen estable de una genealogía con la finalidad de provocar un desplazamiento en el modo de ordenar el relato de la memoria para dar cabida a otra lógica más sensible a las zonas oscuras. Fernando sólo busca contaminar la lógica del sentido, el lenguaje, el "yo" que se supone en armonía con el mundo. A la figura de un heredero que asume el legado pasivamente se contrapone la de otro que muestra la inestabilidad del patrimonio, sus inconsistencias, insolvencias y carencias en un evidente balance deficitario.

Ante una visión de la historia acumulativa que pretende inscribir al sujeto en una comunidad nacional y familiar a la que le corresponde una identidad específica, el narrador opone otro relato que además señala la violencia del relato hegemónico que niega y silencia la existencia de otras voces:

Y he aquí que volviéndome del país del peculado al país de los sicarios suenan afuera unos tiros de ametralladora, y el alma que me habían descosido los zancudos con sus cuchillas de afeitar me la vuelven a coser a balas las ráfagas de la metralleta: tas-tas-tas-tas-tas-tas-tas. Colombia asesina, malapatria, país hijo de puta engendro de España, ¿ ¿a quién estás matando ahora, loca? ¡Cómo hemos progresado en estos años! Antes nos bajábamos la cabeza a machete, hoy nos despachamos con mini-Uzis. (124)

El narrador, al subrayar el crimen y la violencia como rasgos distintivos del proceso de formación nacional, realiza un gesto de interpretación beligerante, lo cual equivale a decir que está inscribiendo su propia experiencia del pasado a través de un acto socialmente simbólico que supone un posicionamiento político (Jameson 18). Dicha acción no busca representar la verdad del pasado en tanto verdad ni subsanar los errores y quiebres infligidos a la nación concebida como entidad indivisa capaz de ser sostenida en el tiempo y capitalizar identidad colectiva, sino romper con la versión unívoca y totalizante de la historia nacional mostrando otra aproximación a sus contenidos:

Machete conservador o liberal, compatriota, paisano, hermano, que saltabas desde el rastrojo a mansalva a cortar los fríos rayos de la luna con tu filo rojo de sangre, ya te cambiaron, ya te olvidaron, pero yo no, aquí estoy yo el que nunca olvido para rezarte y evocarte y recordarte y recordarle a tu Colombia 
desmemoriada, ingrata, que tú exististe un día en que fuiste el rey de la noche. (El desbarrancadero 124)

En el gesto de Vallejo de reescribir el pasado a contrapelo puedo ver la necesidad de un sujeto por reconstruir y producir su propio sentido de la memoria y el recuerdo. En la descripción que a lo largo de la novela hace Fernando del pasado de Colombia hay un registro de su propio padecimiento del tiempo nacional que pone al descubierto los crímenes del pasado, las luchas intestinas y guerras fratricidas que han arrojado un saldo sangriento y que, a su vez, han tenido derivas nefastas en la genealogía familiar. El machete que con su filo cercenaba cabezas no puede quedar en el olvido, es necesario evocarlo para enfrentar los males del presente. El pasado nacional es visto desde el familiar, y el heredero sugiere la instauración de un nuevo principio organizador de su genealogía en el afecto como un estado que lo aproxima al pasado que se desea preservar y continuar. En este sentido, el afecto es una fuerza capaz de alterar la trama del pasado, de "afectarla". Es decir, hay una dialéctica amor/odio que circunscribe la relación con la familia y la nación. El amor está relacionado con la abuela, el padre y el hermano Darío; el odio con la madre y el hermano menor. El amor está vinculado con la lengua castellana y algunas figuras de intelectuales que el narrador admira; el odio con la Iglesia y las instituciones del Estado.

Los "buenos" afectos producen en el heredero estados de nostalgia así como la necesidad de responder a la deuda contraída con esas figuras que le permiten poner a salvo una parte de su herencia. Este recorrido por las zonas excepcionales del pasado están asociados a lugares y objetos que desplazan el relato desencantado y furibundo sobre el pasado hacia otro lugar en el que es posible reconocer otra forma de intensidad basada en la ternura, el amor, el deseo de preservar el recuerdo.

Uno de los objetos que dispara "la buena memoria" en Fernando y lo inserta en una lógica de producción significante alternativa a la deficitaria que pareciera arrojar la herencia recibida es el sillón de la abuela Raquel: "...De la biblioteca traje el sillón de la abuela (el sillón donde se sentó la abuela en sus últimos años a morir) y una silla para poner mi ropa..." (El desbarrancadero 65). En efecto, la mecedora evoca en el narrador la nostalgia por los días de infancia en la hacienda Santa Anita, ubicada en las afueras de la ciudad de Medellín. Esa hacienda lo insta a reflexionar sobre la vertiginosidad de los cambios en su ciudad natal. Santa Anita es la imagen bucólica de otros tiempos, un lugar que devino en área suburbana. El recuerdo por la hacienda de sus abuelos maternos se va haciendo cada vez más intenso en la medida que describe las modificaciones que la modernidad 
causa en su espacio de origen, volviéndolo un lugar extraño, totalmente ajeno a lo que fue en su momento cuando era niño.

Este desplazamiento del recuerdo hacia la evocación de la infancia no sólo responde a la melancolía por la modificación de la ciudad, golpeada por la pobreza, la desigualdad y la violencia, sino también al cambio ocurrido en su familia y en su propia identidad. De esta manera, el narrador va meciendo el recuerdo de aquello que desea preservar como si fuera un vaivén monótono y repetitivo, quizás para hacer el balance afectivo de su relación con la abuela mientras acompaña al hermano Darío en el tránsito hacia la muerte:

-A que no saben qué se ponía a hacer la abuela cuando temblaba-dije por decir para que no volviera el silencio.

-A rezar el Magníficat -contestó Darío. ¡Qué bien te acordaste, hermano! Te evoco ahora con ella a mi lado de niños en el corredor delantero de Santa Anita florecido de azaleas y geranios, y en sus zunchos colgantes el heno, las alegres melenas, que se mecían al vaivén de la furia de la tierra que no era más que la sinrazón del cielo.

-Ay niños dejen de moverme la mecedora que me van a marear-decía la abuela.

-¡Si no te la estamos moviendo, abuelita. Es que está temblando.

- ¿ Temblando? ¡Ay! -gritaba como si la hubiera picado un alacrán. (99-100)

La evocación de sus primeros años de vida en Santa Anita constituye, entonces, una acción nostálgica por la pérdida de los lugares prístinos de Antioquia, al mismo tiempo que por su infancia extraviada, por la modificación que ha sufrido su identidad producto de la voracidad implacable de los acontecimientos familiares y nacionales, además de una modernidad desbordada y desequilibrada:

Ay abuela si me oyeras, si vivieras, si supieras en lo que se han convertido mi vida y este país y esta casa, ya ni nos reconocerías. En mi cuarto escueto en que la noche empantanada no avanza, mirando por entre las tinieblas sin ver, miro el sillón vacío de la abuela, el sillón en que la abuela se sentaba a oír correr las horas cuando el abuelo se murió y ya no tuvo aliciente para seguir viviendo y se quedó mirando al techo. ¡Aliciente! La palabra es suya, de ella, y también ya se murió. Se murió y ni nos dimos cuenta. (103)

Este cuadro hace que el heredero se quede, como la abuela tras la muerte del marido, "mirando el techo", como si no tuviera lugar alguno para habitar sino el de ese sillón borrado por la caída de la casa y de la sangre. Ante una falta tan irreparable solo queda el recuerdo como gesto de inconformidad y rebeldía ante el desmoronamiento del hogar y el país. 
Otro de los objetos que responde al recuerdo de Fernando es la biblioteca de la casa del Barrio de Laureles donde pasó la infancia y juventud. Un lugar que también sufrió las modificaciones del tiempo, donde el espacio se hizo cada vez más reducido debido al incremento de los miembros de la familia, del nacimiento descontrolado de otros hermanos que no cabían y, sin embargo, había que ubicarlos a pesar de la escasez y la privación que afectaba a un cuerpo tan exigente de bocas que alimentar. Ese estudio era el lugar donde solía reunirse con el padre a conversar: "...Ahí, instalados en esa atalaya desde donde dominábamos a Colombia y sus miserias, hablábamos por horas y horas de nuestra pobre patria, de nuestra patria exangüe que se nos estaba yendo entre derramamientos de sangre y de petróleo saqueada por los funcionarios, sobornada por el narcotráfico, dinamitada por la guerrilla..." (81-82). Una vez muerto el padre, el estudio pasó a manos de la madre y el hermano menor, al que apoda con el mote de "Gran Guëvón", últimos habitantes de aquella casa cada vez más ajena al narrador.

Mientras acompaña a Darío a lo largo de su enfermedad terminal, Fernando evoca las imágenes de los últimos días vividos junto al padre, otras de la figuras de la "buena memoria". Recuerda las largas esperas y noches en vela esperando su muerte que sella por completo el derrumbe de su hogar:

No había transcurrido ni un segundo, ni entrado un mililitro siquiera de Eutanal al torrente de la sangre. Fue fulminante (...) Lo miré cuando sus ojos se inmovilizaban en el vacío. El Tiempo, lacayo de la Muerte, se detuvo: papi había dejado el horror de la vida y había entrado en el horror de la muerte. Había vuelto a la nada, de la que nunca debió haber salido. En ese instante comprendí para qué, sin él saberlo, me había impuesto la vida, para qué había nacido y vivido yo: para ayudarlo a morir. Mi vida entera se agotaba en eso. (132)

La eutanasia aplicada al progenitor marca un corte definitivo con la familia y un distanciamiento de la casa, al mismo tiempo que reubica y redefine su propia vida ahora huérfana o más consciente de las dificultades que toda pertenencia implica. Las circunstancias en las que muere el padre, producto de un cáncer de hígado, mueven al hijo a tomar una decisión sin marcha atrás, en la que "darle la muerte" al progenitor paradójicamente implica un gesto de amor: " ¿Y cómo decirle ahora a papi, que se moría, que lo quería, si en una vida entera nunca me dio la oportunidad?" (92). La remembranza de aquella escena es narrada con tristeza y mucho dolor, el mismo heredero termina por calificar de trágica su existencia ante semejantes hechos. Ahora deberá responder a la inexorable pérdida 
del hermano Darío. De nuevo la muerte une lo que la vida había separado, aquel compañero de infancia y juventud, de homosexualidad compartida, pasiones y vicios por la ciudad de Medellín, ahora se encuentra al borde de la agonía.

En el camino hacia el despeñadero, rumbo a la caída definitiva, Fernando acompaña a Darío en los achaques de la enfermedad, sin ninguna esperanza de recuperación pero movido por el afecto y el deseo de estar junto a su hermano. Con la irrupción del Sida, el narrador siente la llegada inminente de la pérdida absoluta de sus seres más queridos. Ante esta amenaza no hay posibilidad de sobrevivir. Darío decide ir a morir a su hogar de crianza y Fernando acude al llamado para acompañarlo en esos momentos finales:

Por este mismo barrio de Buenos Aires por donde voy ahora bajando y entrando a Medellín, ¡cuántas veces no subimos de salida en ese Studebaker cargado de muchachos! Liberados de la ciudad, bajo la luz de la luna y la turbia mirada de Saturno, con el primer aguardiente y en la primera parada se iban quitando la ropa. Un arroyito tintineante cantaba cerca y mugían las vacas. Muuuu, muuuu, muuuu... ¿Sí te acordás, hermano? Darío: cuando pasen cien años, que son nada y se van rápido, vas a ver que esta ciudad miserable nos va a levantar una estatua. (141-142)

La agonía de Darío le permite al narrador un recorrido por los momentos compartidos del pasado relacionados con experiencias vividas junto a él. Este relato cumple la función de unir, en el momento final, a los dos parientes como si la memoria pudiera volverlos más hermanos en la solidaridad de la catástrofe. Puedo entrever el profundo dolor que genera en Fernando el deterioro paulatino de su hermano, la nostalgia por recuperar momentos felices y, al mismo tiempo, la activación de otra lógica, esta vez, no basada en el odio y la guerra que ha marcado la historia familiar y nacional, sino en el amor y el afecto.

Se trata de otra lógica que no censura sino que reconoce en la homosexualidad otro modo de vivir el afecto, otro modo de hacer comunidad a partir de otras exigencias y necesidades. La homosexualidad compartida por los dos hermanos teje una red solidaria y cómplice que los lleva a compartir vivencias no sólo en Medellín sino en Nueva York, donde Darío desempeñaba el rol de conserje de un condominio que fomenta una política pública orientada a estimular la convivencia de las minorías. La vida los había unido en sus primeros años de infancia, ambos gozaban de una vida plena entre el hogar y las atenciones prodigadas por los abuelos en la finca. Luego vino la juventud y algunas experiencias vividas en Medellín y, tras un largo período de separación, la enfermedad y sus efectos irreversibles hacen que los hermanos vuelvan a unirse (161-162). La agonía de Darío 
es atendida por Fernando, en ese momento ambos retoman el amor que los une más allá del lazo de sangre, mientras sucumben al asedio del recuerdo:

Corrí a su cuarto y no estaba. Lo encontré abajo en el jardín bajo el sol mañanero hojeando un viejo álbum de fotos. Marchitas fotos, descoloridas fotos de lo que un día fuimos en el amanecer del mundo. De papi, de Silvio, de Mario, de Iván, de Elenita, el abuelo, la abuela... Para nunca más.

${ }_{-}$¿Le estás pasando revista al cementerio?

-Mirá.

Y me señaló entre las fotos una de dos niños como de cuatro y cinco años:

-Nosotros.

Él de bucles rubios con un abrigo, yo detrás de él con una camisa a rayas abrazándolo.

${ }_{-}$Eso fuimos nosotros? ¡Cuánta agua ha arrastrado el río! (158)

La fotografía de los hermanos que aparece en la portada de la novela, y que además es mencionada en un momento dado del relato, representa una imagen aislada en la memoria familiar en la medida en que revela otro modo de vivir el vínculo de la sangre basado en el cariño y el reconocimiento del otro. $\mathrm{Al}$ mismo tiempo, esa fotografía señala un momento de convivencia y cariño entre los hermanos, unidos por una afinidad que interrumpe la ley que gobierna la casa e impone otro modo de ser hermanos y de ser familia ajeno a la violencia y odio de su sangre: "Han llovido los años sobre esa foto y ahora mi hermano se está muriendo. Mi hermano pero no por los genes disparatados de una loca sino por el dolor de la vida. Lo mejor que le podía pasar a él era que se muriera. Lo mejor que me pudiera pasar a mí era que él siguiera viviendo. No concebía la posibilidad de vivir sin él" (183).

Esa fotografía tan nombrada en el relato señala una solidaridad entre los hermanos que se recupera en el momento de la muerte de Darío, cuando Fernando acude al llamado del afecto y regresa a la casa para acompañarlo durante su agonía.

Esos objetos arriba descritos -la silla, la biblioteca, la foto- activan en el heredero-narrador la disposición al recuerdo y el reconocimiento de una "memoria buena" que es el único patrimonio que desea rescatar.

Así como en la familia se reconoce la existencia de una zona a salvo del monstruo de la sangre, también en la nación es posible rescatar figuras que permiten una mínima restauración de la imagen de la nación. Me refiero al énfasis de Fernando en la importancia de la lengua castellana como instrumento que, a través de la escritura, logra producir nuevos significados e intervenciones polí- 
ticas dentro del orden simbólico. Es decir, hay un reconocimiento de cómo la "minoración" de la lengua castellana interviene el sentido mayor del Estado y la familia e instaura nuevos significados y respuestas ante el desmoronamiento familiar y nacional. Reescribir la memoria de la familia significa también reescribir la memoria de la nación.

Para Vallejo la lengua es un arma de intervención política para desestabilizar, provocar y confrontar el orden impuesto y para enunciar una praxis que quiebra los consensos y genera desacuerdos. Esa misma lengua es la que le permite a Fernando escribir este antilegado que es la misma novela El desbarrancadero. El heredero-narrador interviene la lengua desde adentro subvirtiendo su lógica, su norma y su gramática con la finalidad de traducir la intensidad de los afectos, de los odios y los amores y hacer de la lengua misma un estado afectado como un devenir mismo de quien la enuncia. Una lengua-Vallejo.

Las consideraciones anteriores muestran, en qué medida, el pasado no se asume pasivamente sino a partir de políticas específicas que encuentran un caudal en la escritura y ponen al desnudo la imposibilidad de una transferencia armónica de la herencia. Es el texto mismo el que sirve como prueba de la intervención que hace el heredero, en la forma de narrar y en los sucesos seleccionados para su rememoración está el gesto subjetivo de aquel que desea (re)ordenar el proceso que lo ha conformado dentro de una imagen de familia y, por ende, de nación. La escritura opera como agente desencadenador de nuevos significados del pasado, en un juego permanente de avance y retroceso (Saraceni, Escribir hacia atrás... 35). Esas fluctuaciones arrojan en la novela de Vallejo un estado deficitario del patrimonio íntimo y familiar, como también del público y nacional; irrupciones iracundas de un narrador que escribe desde la falta. En el análisis sobre El desabarrancadero es perceptible la tensión entre dos formas de narrar la nación, es decir aquella pedagógica o la performativa, donde no es posible la reconciliación. La novela opera en una zona intermedia, en un espacio "liminar" que siempre está a la defensiva y con un tono díscolo e iconoclasta, algo de por sí muy característico de la prosa vallejiana. En todo caso, la herencia descrita por Vallejo en esta novela retrata el desamparo al que el sujeto queda expuesto una vez muerto los seres amados, esa falta se convierte en testimonio del dolor y en furia por el afecto irrecuperable de los que ya no están, pero también en posibilidad de mostrar otro relato del pasado más inconforme y menos dispuesto a la conciliación. 


\section{Obras citadas}

Amado, Ana y Nora Domínguez. Lazos de familia. Herencias, cuerpos, ficciones. Buenos Aires: Paidós, 2002.

Anderson, Benedict. Comunidades imaginadas. México:

Fondo de Cultura Económica, 1997.

Arfuch, Leonor. Crítica cultural entre política y poética. Buenos

Aires: Fondo de Cultura Económica, 2008.

-. El espacio biográfico. Buenos Aires: Fondo de Cultura Económica, 2010.

-. (comp.). Pensar este tiempo: espacios, afectos, pertenencias. Buenos Aires: Paidós, 2005.

Barbosa, Mario y Zenia Yébenes (comps.). Silencios, discursos y miradas sobre la violencia. Madrid: Editorial Anthropos, 2009.

Benjamin, Walter. La dialéctica en suspenso. Santiago de Chile: Universidad ARCIS- LOM Ediciones, 1995.

Beyhaut, Gustavo y Hélène. América Latina: III. De la independencia a la segunda guerra mundial. México: Siglo XXI Editores, 2004.

Bhabha, Homi (comp.). Nación y narración. Buenos Aires: Siglo XXI Editores, 2010.

Castillo Zapata, Rafael. La espiral incesante. Caracas: Fundación Centro de Estudios Latinoamericanos Rómulo Gallegos, 2010.

Cañón M., Luis. El patrón: vida y muerte de Pablo Escobar. Colombia: Planeta, 2002.

Derrida, Jacques. Espectros de Marx. El estado de la deuda, el trabajo del duelo y la Nueva Internacional. Madrid: Editorial Trotta, 1995.

-. Memorias para Paul de Man. Madrid: Editorial Gedisa, 1998.

Franco Ortiz, José Javier. Figuras de la memoria. Caracas:

Monte Ávila Editores Latinoamericana, 2007.

Foucault, Michel. El orden del discurso. Buenos Aires: Tusquets, 1992.

-. Microfísica del Poder. Madrid: La Piqueta, 1980.

Freud, Sigmund. Obras completas. Buenos Aires: Amorrortu Editores, 1996.

Gradowska, Anna. El otoño de la edad moderna: reflexiones sobre el postmodernismo.

Caracas: UCV, Consejo de Desarrollo Científico y Humanístico, 2004.

Halperin Donghi, Tulio. Historia contemporánea de América

Latina. Madrid: Alianza Editorial, 1972.

Huyssen, Andreas. En busca del futuro perdido. Cultura y memoria en tiempos de globalización. México: Fondo de Cultura Económica, 2002.

Izard, Miguel. Tierra Firme, Historia de Venezuela y

Colombia. Madrid: Alianza Editorial, 1987.

Jameson, Fredric. Documentos de cultura, documentos de barbarie. Madrid: Visor, 1989 .

Lacan, Jacques. La familia. Buenos Aires: Editorial Argonauta, 1978. 
Martín, Américo. La violencia en Colombia. Caracas: El Nacional, 2010.

Mato, Daniel. Crítica de la modernidad, globalización y construcción de identidades.

Caracas: UCV, Consejo de Desarrollo Científico y Humanístico, 1995.

Menton, Seymour. La novela colombiana. Bogotá: Fondo de Cultura Económica, 2007.

Molloy, Sylvia. Acto de presencia. La escritura autobiográfica en

Hispanoamérica. México: Fondo de Cultura Económica, 1996.

Nietzsche, Friedrich. Sobre la utilidad y los perjuicios de la historia para la vida. Madrid: Edaf, 2010.

-. La genealogía de la moral. Madrid: Edimat Libros, 2007.

Pacheco, Carlos. "La historia en la ficción hispanoamericana contemporánea: perspectivas y problemas para una agenda crítica". Estudios. Revista de Investigaciones Literarias y Culturales No. 18 (Julio-Diciembre de 2001): 205-224.

Restrepo, Laura. Historia de un entusiasmo. Bogotá: Aguilar, 2005.

Richard, Nelly. Figuras de la memoria: Arte y pensamiento crítico. Buenos Aires: Siglo XXI Editores, 2007.

Roudinesco, Elizabeth. La familia en desorden. Buenos Aires: Fondo de Cultura Económica, 2003.

Sarlo, Beatriz. Tiempo pasado: cultura de la memoria y giro subjetivo. Una discusión. Buenos Aires: Siglo XXI Editores, 2007.

Saraceni, Gina. Escribir hacia atrás: herencia, lengua, memoria. Rosario: Beatriz Viterbo Editora, 2008.

-. La soberanía del defecto. Legado y pertenencia en la literatura latinoamericana contemporánea. Caracas: Editorial Equinoccio, 2012.

Vallejo, Fernando. El desbarrancadero. Bogotá: Alfaguara, 2001.

-. La virgen de los Sicarios. Buenos Aires: Suma de Letras, 2002.

Williams, Raymond. Marxismo y literatura. Barcelona: Ediciones Península, 1997. 